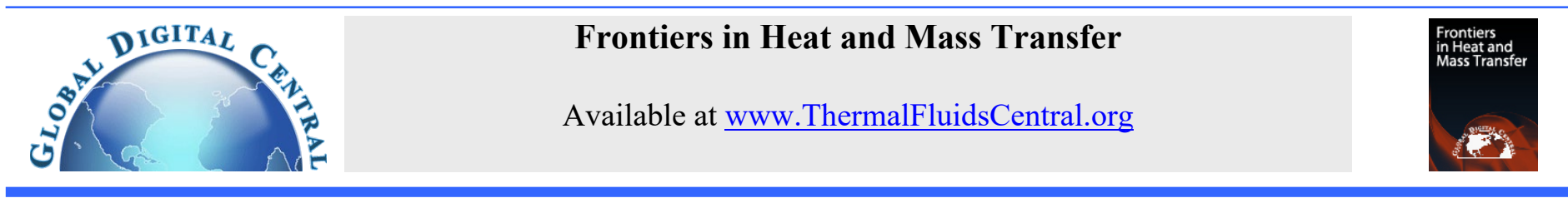

\title{
HALL AND ION SLIP EFFECTS ON AG - WATER BASED MHD NANOFLUID FLOW OVER A SEMI-INFINITE VERTICAL PLATE EMBEDDED IN A POROUS MEDIUM
}

\author{
CH. Baby Rani ${ }^{\mathrm{a}}$, N. Vedavathi ${ }^{\mathrm{b}}$, K.S. Balamurugan ${ }^{\mathrm{c}}$ and G. Dharmaiah ${ }^{\mathrm{d} *}$ \\ ${ }^{a}$ Department of Mathematics, V. R. Siddhartha Engineering College, Kanuru, Andhra Pradesh, 520007, India. \\ ${ }^{b}$ Department of Mathematics, Koneru Lakshmaiah Education Foundation, Vaddeswaram, Guntur, Andhra Pradesh, 522502, India. \\ ${ }^{c}$ Department of Mathematics, RVR \& JC College of Engineering, Chowdavaram, Guntur, Andhra Pradesh, 522019, India. \\ ${ }^{d}$ Department of Mathematics, Narasaraopeta Engineering College, Yellamanda, Narasaraopet, Andhra Pradesh, 522601, India.
}

\begin{abstract}
The present work provides an analysis of the Dufour, radiation absorption, Hall and ion slip effects on MHD free convective rotating flow of Agwater based nanofluid past a semi-infinite permeable moving plate with constant heat source. In this regard, metal will be considered as nanoparticles with water as base fluid. Governing nonlinear boundary layer equations and boundary conditions are transformed into a system of nonlinear ordinary coupled differential equations and are solved by perturbation technique. Effects of different parameters on skin friction coefficient, local Nusselt number and Local Sherwood number are also discussed.
\end{abstract}

Keywords: Ag-water nanofluid, Dufour effect, Hall and ion slip, Radiation Absorption, Rotation.

\section{INTRODUCTION}

There is an increasing interest of the researchers in the analysis of nanofluids. The word nanofluid was introduced by Choi. In fact a nanouid is a dilute suspension of solid nanoparticles with the average size below $100 \mathrm{~nm}$ in a base fluid, such as: water, oil and ethylene glycol. Nano comes from the Greek word for dwarf. The prefix nano means a factor of one billionth $\left(10^{-9}\right)$ and can be applied, e.g., to time(nano second), volume(nano liter), weight(nano gram)or length(nano meter or $\mathrm{nm}$ ). In its popular use nano refers to length, and the nanoscale usually refers to a length from the atomic level of around $1 \mathrm{~nm}$ upto $100 \mathrm{~nm}$. Some examples are 1) A sheet of paper is about 100,000 nanometers thick. 2) A human hair is approximately 80,000100,000 nanometers wide. 3) A finger nail grows about one nanometer per second. 4) A single gold atom is about a third of a nanometer in diameter. 5) On a comparative scale, if the diameter of a marble was one nanometer, then diameter of the Earth would be about one meter. Nanouids exhibit thermal properties superior to those of the base fluids of the conventional particle fluid suspensions. The nanoparticles can be made of metal, metal oxide, carbide, nitride and even immiscible nanoscale liquid droplets. Some advantages of nanouids which make them useful are: a tiny size, along with a large specific surface area, high effective thermal conductivity and high stability and less clogging and abrasion. The materials with sizes of nanometers possess unique physical and chemical properties. They can flow smoothly through micro channels without clogging them because it is small enough to behave similar to liquid molecules.

Turkyilmazoglu (2014) has studied exact analytical solutions for heat and mass transfer of MHD slip flow in nanofluids. Das and Rana (2015) have analyzed the natural convective magneto-nanofluid flow and radiative heat transfer past a moving vertical plate. Satya Narayana et al. (2015) have studied the influence of thermal radiation and heat source on MHD nanofluid past a vertical plate in a rotating system. Das et al. (2016) have examined the transient natural convection in a vertical channel filled with nanofluids in the presence of thermal radiation. Venkateswarlu and Satya Narayana (2015) have analysed the chemical reaction and radiation absorption effects on the flow and heat transfer of a nanofluid in a rotating system. Mahanthesh et al. (2016) have investigated the heat and mass transfer effects on the mixed convective flow of chemically reacting nanofluid past a moving/stationary vertical plate. Dharmaiah et al. (2017) examined analysis of heat and mass transfer on MHD flow of nanofluid over a semi infinite moving surface with diffusion thermo. Vedavathi et al. (2017) discussed heat transfer on MHD nanofluid flow over a semiinfinite flat plate embedded in a porous medium with radiation absorption, heat source and diffusion thermo effect. Dharmaiah et al. (2018) presented MHD boundary layer flow and heat transfer of a nanofluid past a radiative and impulsive vertical plate. Vedavathi et al. (2019) proposed a study on MHD boundary layer flow rotating frame nanofluid with chemical reaction.

Ramprasad et al. (2019) numerically studied a study on $\mathrm{Al}_{2} \mathrm{O}_{3}-\mathrm{H}_{2} \mathrm{O}$ nanofluid in the presence of constant heat source. Veera Krishna and Chamkha (2019) presented Hall and ion slip effects on MHD rotating boundary flow of nanofluid past an infinite vertical plate embedded in a porous medium. Hydromagnetic nanofluid convection flows involving heat and mass transfer received a special attention (see for instance the works of Veeresh et al. (2017), Sathish Kumar et al. (2017), Kumaresan et al. (2018), Rashad et al. (2018) and Wakif et al. (2019)). Dharmaiah et al. (2019) have been discussed that viscous dissipation effect on transient aligned magnetic free convective flow past an inclined moving plate. Srinivasacharya and Shafeeurrahaman deliberated the mixed convection flow of nanofluid in a vertical channel with hall and ion-slip effects. Abdullah et al. (2017) proposed that the effect of magnetic field

\footnotetext{
${ }^{*}$ Corresponding Author: dharma.g2007@gmail.com
} 
inclination on magnetoconvective induced irreversibilities in a cntwater nanofluid filled cubic cavity. Oyelakin et al. (2017) described that an unsteady MHD three-dimensional casson nanofluid flow over a porous linear stretching sheet with slip condition. Ramesh and Gireesha (2017) have been studied that a non-linear radiative flow of nanofluid past a moving/stationary riga plate. Stanford Shateyi (2017) has been stated that heat and mass transfer for natural convection MHD flow over a permeable moving vertical plate with convective boundary condition in the presence of viscous dissipation. Seth et al., (2017) examined that effect of hall current on MHD natural convection heat and mass transfer flow of rotating fluid past a vertical plate with ramped wall temperature. Arifuzzaman et al. (2017) analyzed that MHD maxwell fluid flow in presence of nano-particle through a vertical porous-plate with heat-generation, radiation absorption and chemical reaction. Yongbin Zhang (2017) has been reported that an influence of pore wall surface property on flux of cylindrical-shaped nanoporous filtering membrane. Mahantesh and Shakunthala (2017) considered that the flow and heat transfer of carbon nanofluids over a vertical plate. Habib-OlahSayehvand et al. (2017) have been documented that MHD nanofluid flow with viscous dissipation and joule heating through a permeable channel. Ananda Reddy et al. (2018) examined that the radiation and dufour effects on laminar flow of a rotating fluid past a porous plate in conducting field. Rashad et al. (2018) have been investigated that mixed bioconvection flow of a nanofluid containing gyrotactic microorganisms past a vertical slender cylinder.

Samrat et al. (2018) have been developed that an impact of thermal radiation and chemical reaction on unsteady $2 \mathrm{~d}$ flow of magneticnanofluids over an elongated plate embedded with ferrous nanoparticles. Maouassi et al. (2018) have discussed that heat exchanges intensification through a flat plat solar collector by using nanofluids as working fluid. Dharmaiah et al. (2018) have been deliberated that heat and mass transfer on MHD fluid flow over a semi infinite flat plate with radiation absorption, heat source and diffusion thermo effect. Hong $\mathrm{Hu}$ and Chung (2018) studied that a molecular dynamics simulation of nanoscale water vapor absorption on the surface of libraqueous solution. Tashkandi and Abdelkarim Aydi (2018) analyzed that heat transfer intensification in a $3 \mathrm{~d}$ cavity using hybrid cnt-al2o3 (15-85\%) nanofluid. Yashwant Singh et al. (2018) described that a development of new correlations for nusselt number and friction factor of tio2/water based nanofluid flow in v-pattern protrusion ribbed square channel.

Motivated by the above reference work and the numerous possible industrial applications of the problem, it is of paramount interest to investigate the effects of diffusion-thermo, radiation-absorption and Hall and ion slip, chemical reaction and heat source on MHD nanofluid flow in a rotating system with spherical, uniform shape and size type nanoparticles. It is worth mentioning that the nanofluid model proposed by Buongiorno (2006) is used by many recent studies (Rana and Bharava, 2012; Alsaedi and Hayat, 2012). However, we are following the nanofluid model proposed by Tiwari and Dass (2007), which is being used by many current researches Hamad and Pop (2011); Hamad and Ferdows (2012); Norifiah Bachok (2012) on various flow fields.

\section{ANALYSIS AND METHODOLOGY OF THE FLOW OF THE PROBLEM}

We consider an unsteady three-dimensional flow of an electrically conducting incompressible nanofluid past a semi-infinite vertical permeable plate with the Hall and ion slip effects. A uniform external magnetic field $\mathrm{B}_{0}$ is taken to be acting along the $\mathrm{z}^{*}$ axis. The flow is assumed to be in the $\mathrm{x}$ - direction which is taken along the plate in the upward direction and $\mathrm{z}^{*}$ axis is normal to the plate. Also it is assumed the whole system is rotated with a constant vector $\Omega$ about $z^{*}$ - axis. The fluid is assumed to be gray, absorbing emitting but not scattering medium. The radiation heat flux in $\mathrm{x}^{*}$ - direction is considered negligible in comparison that in the $\mathrm{z}^{*}$-direction. Due to semi-infinite plate surface assumption the flow variables are functions of $\mathrm{z}$ and time $\mathrm{t}$ only. The governing equations for this investigation are given by:

$\frac{\partial w^{*}}{\partial z^{*}}=0$

$\frac{\partial u^{*}}{\partial t^{*}}+w^{*} \frac{\partial u^{*}}{\partial z^{*}}-2 \Omega v^{*}=\frac{\mu_{n f}}{\rho_{n f}} \frac{\partial^{2} u^{*}}{\partial z^{* 2}}+\frac{B_{0} J_{y}}{\rho_{n f}}-\frac{\mu_{n f}}{\rho_{n f}} \frac{u^{*}}{k^{*}}+g(\rho \beta)_{n f}\left(T-T_{\infty}\right)$

$\frac{\partial v^{*}}{\partial t^{*}}+w^{*} \frac{\partial v^{*}}{\partial z^{*}}+2 \Omega u^{*}=\frac{\mu_{n f}}{\rho_{n f}} \frac{\partial^{2} v}{\partial z^{* 2}}-\frac{B_{0} J_{x}}{\rho_{n f}}-\frac{\mu_{n f}}{\rho_{n f}} \frac{v^{*}}{k^{*}}$

$\frac{\partial T^{*}}{\partial t^{*}}+w^{*} \frac{\partial T^{*}}{\partial z^{*}}=\alpha_{n f} \frac{\partial^{2} T^{*}}{\partial z^{* 2}}-\frac{Q^{*}}{\left(\rho C_{p}\right)_{n f}}\left(T^{*}-T_{\infty}\right)+$

$\frac{Q_{l}}{\left(\rho C_{p}\right)_{n f}}\left(C^{*}-C_{\infty}\right)+\frac{D_{m} K_{T}}{C_{s}\left(\rho C_{p}\right)_{n f}} \frac{\partial^{2} C^{*}}{\partial z^{* 2}}$

$\frac{\partial C^{*}}{\partial t^{*}}+w^{*} \frac{\partial C^{*}}{\partial z^{*}}=D_{B} \frac{\partial^{2} C^{*}}{\partial z^{* 2}}-K_{l}\left(C^{*}-C_{\infty}\right)$

The corresponding boundary conditions are

$u^{*}=0, v^{*}=0, T^{*}=T_{\infty}, C=C_{\infty} \quad$ for $t \leq 0$

$u^{*}=U_{0}, v^{*}=0, T^{*}=T_{w}+\left(T_{w}-T_{\infty}\right) \varepsilon e^{i \omega t}$,

$C^{*}=C_{w}+\left(C_{w}-C_{\infty}\right) \varepsilon e^{i \omega t} \quad$ at $\left.z=0\right\} t>0$

$u^{*}=0, v^{*}=0, T^{*}=T_{\infty}, C^{*}=C_{\infty}$ as $z \rightarrow \infty$

The electron-atom collision frequency is assumed to be very high, so that Hall and ion slip currents cannot be neglected. Hence, the Hall and ion slip currents give rise to the velocity in y-direction. When the strength of the magnetic field is very large, the generalized Ohm's law is modified to include the Hall and ion slip effect (Sutton and Sherman (1965)).

$J=\sigma(E+V \times B)-\frac{\omega_{e} \tau_{e}}{B_{0}}(J \times B)+\frac{\omega_{e} \tau_{e} \tau_{i}}{B_{0}^{2}}((J \times B) \times B)$

Further it is assumed that $\omega_{e} \tau_{e} \sim O(1)$ and $\omega_{i} \tau_{i} \ll 1$, in the Eq. (8), the electron pressure gradient and thermo-electric effects are neglected, i.e., the electric field $E=0$ (Srinivasacharya and Shafeeurrahman (2017)) under these assumptions, the Eq. (8) reduces to

$$
\left.\begin{array}{c}
\left(1+\beta_{i} \beta_{e}\right) J_{x}+\beta_{e} J_{y}=\sigma B_{0} v \\
\left(1+\beta_{i} \beta_{e}\right) J_{y}-\beta_{e} J_{x}=-\sigma B_{0} u
\end{array}\right\}
$$

On solving the set of equations set (9) we can get

$$
\left.\begin{array}{c}
J_{x}=\sigma B_{0}\left(\alpha_{2} u+\alpha_{1} v\right) \\
J_{y}=-\sigma B_{0}\left(\alpha_{2} v-\alpha_{1} u\right)
\end{array}\right\}
$$

Where $\alpha_{1}=\frac{1+\beta_{e} \beta_{i}}{\left(1+\beta_{e} \beta_{i}\right)^{2}+\beta_{e}^{2}} \& \alpha_{2}=\frac{\beta_{e}}{\left(1+\beta_{e} \beta_{i}\right)^{2}+\beta_{e}^{2}}$

Substituting the set of equations (10) in equations (2) and (3), we get

$$
\frac{\partial u^{*}}{\partial t^{*}}+w^{*} \frac{\partial u^{*}}{\partial z^{*}}-2 \Omega v^{*}
$$

$=\frac{\mu_{n f}}{\rho_{n f}} \frac{\partial^{2} u^{*}}{\partial z^{* 2}}+\frac{\sigma_{n f} B_{0}^{2}\left(\alpha_{2} v^{*}-\alpha_{1} u^{*}\right)}{\rho_{n f}}-\frac{\mu_{n f}}{\rho_{n f}} \frac{u^{*}}{k^{*}}+(\rho \beta)_{n f} g\left(T^{*}-T_{\infty}\right)$

$\frac{\partial v^{*}}{\partial t^{*}}+w^{*} \frac{\partial v^{*}}{\partial z^{*}}+2 \Omega u^{*}$

$=\frac{\mu_{n f}}{\rho_{n f}} \frac{\partial^{2} v^{*}}{\partial z^{* 2}}-\frac{\sigma_{n f}}{\rho_{n f}} B_{0}^{2}\left(\alpha_{2} u^{*}+\alpha_{1} v^{*}\right)-\frac{\mu_{n f}}{\rho_{n f}} \frac{v^{*}}{k^{*}}$

Let $q^{*}=u^{*}+i v^{*}$

Equation (11) \& (12) becomes as 


$$
\begin{aligned}
& \frac{\partial q^{*}}{\partial t^{*}}+w^{*} \frac{\partial q^{*}}{\partial z^{*}}+2 i \Omega q^{*} \\
& =\frac{\mu_{n f}}{\rho_{n f}} \frac{\partial^{2} q^{*}}{\partial z^{* 2}}-\frac{\sigma_{n f}}{\rho_{n f}} B_{0}^{2}\left(\alpha_{1}+i \alpha_{2}\right) q^{*}-\frac{\mu_{n f}}{\rho_{n f}} \frac{q^{*}}{k^{*}}+g(\rho \beta)_{n f}\left(T^{*}-T_{\infty}\right)
\end{aligned}
$$

The solution of equation (1) is $w=-w_{0}$

Where the constant $-w_{0}$ represents the normal velocity at the plate which is positive suction $\left(w_{0}>0\right)$ and negative for blowing injection $\left(w_{0}<0\right)$. The non-dimensional variables considered as

$$
\begin{aligned}
& z=\frac{U_{0} z^{*}}{v_{f}}, t=\frac{U_{0}^{2} t^{*}}{v_{f}},\left(\rho C_{p}\right)_{f}=\frac{\operatorname{Pr} K_{f}}{v_{f}}, w=\frac{v_{f} w^{*}}{U_{0}^{2}}, q=\frac{q^{*}}{U_{0}}, \\
& Q=\frac{Q^{*} v_{f}^{2}}{K_{f} U_{0}^{2}}, \theta=\frac{T^{*}-T_{\infty}}{T_{w}-T_{\infty}}, \psi=\frac{C^{*}-C_{\infty}}{C_{w}-C_{\infty}}, M^{2}=\frac{\sigma_{n f} B_{0}^{2} v_{f}}{\rho_{f} U_{0}^{2}}, \\
& G r=\frac{(\rho \beta)_{f} g v_{f}\left(T_{w}-T_{\infty}\right)}{U_{0}^{3}}, K=\frac{k^{*} \rho_{f}^{2}}{v_{f}^{2}}, S=\frac{w_{0}}{U_{0}}, R=\frac{2 \Omega v_{f}}{K_{f} U_{0}^{2}}, \\
& \beta_{i}=\omega_{i} \tau_{i}, \beta_{e}=\omega_{e} \tau_{e}, S c=\frac{v_{f}}{D_{B}}, K r=\frac{K_{l} v_{f}}{U_{0}^{2}}, Q_{L}=\frac{Q_{l} v_{f}^{2}\left(C_{w}-C_{\infty}\right)}{K_{f} U_{0}^{2}\left(T_{w}-T_{\infty}\right)}, \\
& D u=\frac{D_{m} K_{T}\left(C_{w}-C_{\infty}\right)}{K_{f} C_{s}\left(T_{w}-T_{\infty}\right)}
\end{aligned}
$$

On the other hand, the coefficients of thermal expansion of the fluid and the solid, the densities of the fluid and of the solid fractions, the density of the nanofluid, the viscosity of the nanofluid, the thermal diffusivity of the nanofluid, and the heat capacitance of the nanofluid, which are defined as (see Abbasi(2015)).

$$
\begin{aligned}
& \rho_{n f}=(1-\phi) \rho_{f}+\phi \rho_{s} ;\left(\rho C_{p}\right)_{n f}=(1-\phi)\left(\rho C_{p}\right)_{f}+\phi\left(\rho C_{p}\right)_{s} \\
& (\rho \beta)_{n f}=(1-\phi)(\rho \beta)_{f}+\phi(\rho \beta)_{s} \\
& \frac{K_{n f}}{K_{f}}=\left(\frac{K_{s}+2 K_{f}-2 \phi\left(K_{f}-K_{s}\right)}{K_{s}+2 K_{f}+2 \phi\left(K_{f}-K_{s}\right)}\right) ; \mu_{n f}=\frac{\mu_{f}}{(1-\phi)^{2.5}} ; \alpha_{n f}=\frac{K_{n f}}{\left(\rho C_{p}\right)_{n f}}
\end{aligned}
$$

Using dimensionless variables, the equations (13), (4) \& (5) with the boundary conditions (6)-(7), we obtain,

$d_{1}\left[\frac{\partial q}{\partial t}-S \frac{\partial q}{\partial z}+i R q\right]=d_{4} \frac{\partial^{2} q}{\partial z^{2}}-M^{2} q\left(\alpha_{1}+i \alpha_{2}\right)-d_{4} \frac{q}{K}+d_{1} d_{2} G r \theta$

$d_{3}\left(\frac{\partial \theta}{\partial t}-S \frac{\partial \theta}{\partial z}\right)=\frac{1}{\operatorname{Pr}}\left[d_{5} \frac{\partial^{2} \theta}{\partial z^{2}}-Q \theta+Q_{L} \psi+D u \frac{\partial^{2} \psi}{\partial z^{2}}\right]$

$\frac{\partial \psi}{\partial t}-S \frac{\partial \psi}{\partial z}=\frac{1}{S c} \frac{\partial^{2} \psi}{\partial z^{2}}-K r \psi$

The corresponding boundary conditions are

$q=0, \theta=0, \psi=0 \quad$ at $t \leq 0$

$\left.\begin{array}{c}q=1, \theta=1+\varepsilon e^{i \omega t}, \psi==1+\varepsilon e^{i \omega t} \text { at } z=0 \\ q=0, \theta=0, \psi=0 \text { as } z \rightarrow \infty\end{array}\right\}$ at $t>0$

Eqs. (16)-(18) are coupled non-linear partial differential equations whose solutions in closed-form are difficult to obtain. To solve these equations by converting into ordinary differential equations, the unsteady flow is superimposed on the mean steady flow, so that in the neighborhood of the plate, the expressions for velocity, temperature and concentration are assumed $(\varepsilon<<1)$ as

$$
\begin{aligned}
& q=q_{0}+\varepsilon e^{i \omega t} q_{1}+O\left(\varepsilon^{2}\right), \\
& \theta=\theta_{0}+\varepsilon e^{i \omega t} \theta_{1}+O\left(\varepsilon^{2}\right), \\
& \psi=\psi_{0}+\varepsilon e^{i \omega t} \psi_{1}+O\left(\varepsilon^{2}\right)
\end{aligned}
$$

Equations (16)-(18) are reduced to

$d_{4} q_{1}^{\prime \prime}+d_{1} S q_{1}^{\prime}-M_{2} q_{1}=-d_{1} d_{2} G r \theta_{1}$

$d_{4} q_{0}^{\prime \prime}+d_{1} S q_{0}^{\prime}-M_{1} q_{0}=-d_{1} d_{2} G r \theta_{0}$

$d_{5} \theta_{1}^{\prime \prime}+d_{3} \operatorname{Pr} S \theta_{1}^{\prime}-\left(Q+d_{3} \operatorname{Pr} i \omega\right) \theta_{1}=-Q_{L} \psi_{1}-D u \psi_{1}^{\prime \prime}$

$d_{5} \theta_{0}^{\prime \prime}+d_{3} \operatorname{Pr} S \theta_{0}^{\prime}-Q \theta_{0}=-Q_{L} \psi_{0}-D u \psi_{0}^{\prime \prime}$

$\psi_{1}^{\prime \prime}+S S c \psi_{1}^{\prime}-[S c(K r+i w)] \psi_{1}=0$

$\psi_{0}^{\prime \prime}+S S c \psi_{0}^{\prime}-\operatorname{KrSC} \psi_{0}=0$

The corresponding boundary conditions are

$q_{1}=0, q_{0}=1, \theta_{1}=1, \theta_{0}=1, \psi_{1}=1, \psi_{0}=1 \quad$ at $\quad z=0$

$q_{1}=0, q_{0}=0, \theta_{1}=0, \theta_{0}=0, \psi_{1}=0, \psi_{0}=0$ as $z \rightarrow \infty$

Where $M_{1}=M^{2}\left(\alpha_{1}+i \alpha_{2}\right)+\frac{d_{4}}{K}+d_{1} i R$ and $M_{2}=M_{1}+d_{1} i \omega$

On solving the equations (22)-(27) with (28) \& (29), we can obtain

$q_{1}=B_{8} e^{-m_{6} z}+B_{6} e^{-m_{4} z}+B_{7} e^{-m_{2} z}$

$q_{0}=B_{5} e^{-m_{5} z}+B_{3} e^{-m_{3} z}+B_{4} e^{-m_{1} z}$

$\theta_{1}=B_{2} e^{-m_{4} z}+A_{2} e^{-m_{2} z}$

$\theta_{0}=B_{1} e^{-m_{3} z}+A_{1} e^{-m_{1} z}$

$\psi_{1}=e^{-m_{2} z}$

$\psi_{0}=e^{-m_{1} z}$

Finally, the velocity, temperature, concentration, skin-friction, Nusselt number and Sherwood number at the plate in the dimension form are given by

$$
\begin{aligned}
& q(z, t)=q_{0}(z, t)+\varepsilon e^{i w t} q_{1}(z, t) \\
& \theta(z, t)=\theta_{0}(z, t)+\varepsilon e^{i w t} \theta_{1}(z, t) \\
& \psi(z, t)=\psi_{0}(z, t)+\varepsilon e^{i w t} \psi_{1}(z, t) \\
& C_{f}=-\left(\frac{\partial q}{\partial z}\right)_{z=0}, N u=-\left(\frac{\partial \theta}{\partial z}\right)_{z=0} \& S h=-\left(\frac{\partial \psi}{\partial z}\right)_{z=0}
\end{aligned}
$$

Where

$$
\begin{aligned}
& d_{1}=\left(1-\phi+\phi\left(\frac{\rho_{s}}{\rho_{f}}\right)\right), d_{2}=\left(1-\phi+\phi\left(\frac{(\rho \beta)_{s}}{(\rho \beta)_{f}}\right)\right), \\
& d_{3}=\left(1-\phi+\phi\left(\frac{\left(\rho C_{p}\right)_{s}}{\left(\rho C_{p}\right)_{f}}\right)\right), d_{4}=\frac{1}{(1-\phi)^{2.5}}, d_{5}=\frac{1+2 \phi+2(1-\phi)\left(\frac{K_{f}}{K_{s}}\right)}{1-2 \phi+2(1+\phi)\left(\frac{K_{f}}{K_{s}}\right)}
\end{aligned}
$$

\section{RESULTS AND DISCUSSIONS}

In order to carried out the significant features of the flow, heat and mass transfer characteristics with nanoparticles, the results are presented in Figs. 1-21 and in Tables 1-3. The computational discussion has been done on the effects of flow parameters on velocity, temperature and concentration of nano-particles, the skin friction, the rate of heat and mass transfer coefficients. The thermo-physical properties of the base fluid (water) and silver which were used for code validation are given in Table 4. For the velocity profiles and skin friction, $\varepsilon=0.01, \omega=\pi / 6$, $\operatorname{Pr}=6.2, \mathrm{Q}=2, \mathrm{Sc}=0.22$ has chosen by us while the remaining parameters are varied over a range. 


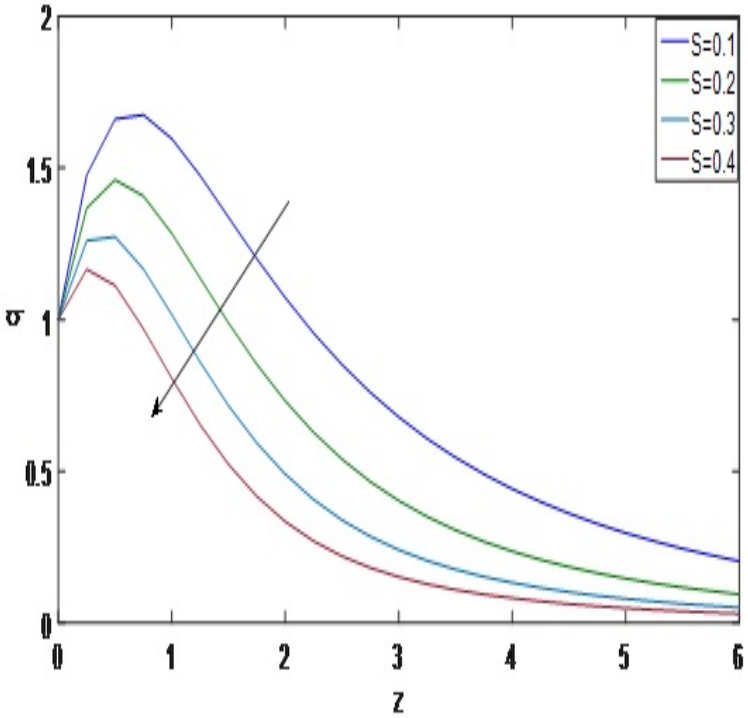

Fig. 1 The velocity profiles for q against $\mathrm{S}$

Figs. $1 \& 17$ demonstrates the effect of suction parameter $\mathrm{S}$ on both fluid velocity $\mathrm{q}$ and temperature $\theta$, for nanofluid $\phi=0.15$. As an output of figure, it is seen that the velocity and temperature of the fluid across the boundary layer decreases by increasing the suction parameter $\mathrm{S}$ for nanofluid with nanoparticles $\mathrm{Ag}$. Figures 2 \& 14 depict the effects of solid volume fraction $\phi$ of the nano particle. It is observed that from both figures, by increasing $\phi$, both the nano-fluid velocity and temperature increases. The velocity profiles of q with Hartmann number $\mathrm{M}$ for the nano-particles Ag are presented in Fig. 3. With the increase in $\mathrm{M}$ the velocity $\mathrm{q}$ decelerates. The transverse magnetite field which is applied orthogonally to the direction of flow gives a resistive force known as Lorentz force. This Lorentz force resists the flow of nanofluid therefore the velocity decreases. This force has the tendency to slow down the motion of the fluid in the boundary layer. These results quantitatively agree with the expectations, since magnetic field exerts retarding force on natural convection flow. The velocity profiles of $\mathrm{q}$ with $\mathrm{R}$ are shown in Fig.4. The magnitude of the velocity q reduces with increasing rotation parameter $\mathrm{R}$ from this figure.

Figs. $5 \& 15$ have been plotted to find the variation of nanofluid velocity and temperature profiles for different values of heat generation parameter Q. It is clear that, there is a decrease in the velocity and temperature with increase of Q. This is due to the fact that when heat is absorbed, the buoyancy forces decrease which retard the flow rate and thereby give rise to a decrease in the velocity and temperature profiles. For various values of $\mathrm{Q}_{\mathrm{L}}$, the nanofluid velocity and temperature profiles across the boundary layer are shown in Fig. $6 \&$ 18. It is clear from the graphs that all the nanofluid velocity and temperature profiles increases with increase of QL. This is due to the fact that when heat is absorbed, the buoyancy forces accelerate the flow. Figure 7 illustrates the effect of permeability parameter $\mathrm{K}$ on the nanofluid velocity distribution. It is clear from the figure that as $\mathrm{K}$ increases, the nanofluid velocity also increases. Physically, this means that the porous medium impact on the boundary layer growth is significant due to the increase in the thickness of the thermal boundary layer. It is expected that, an increase in the permeability of the porous medium leads to the rise in the flow of fluid through it. When the holes of the porous medium become large, the resistance of the medium may be neglected. Figure 8 shows the nanofluid velocity profiles for different values of Grashof number Gr. For increasing Grashof number Gr the parallel behaviour is scrutinized from Figure 8. The influence of Diffusion-thermo parameter $\mathrm{Du}$ on the velocity component q increases for Ag- water nanofluids is shown in Fig. 9. It is noticed that the boundary layer thickness increases with $\mathrm{Du}$ for nano-fluid. Hence the hydrodynamic boundary layer

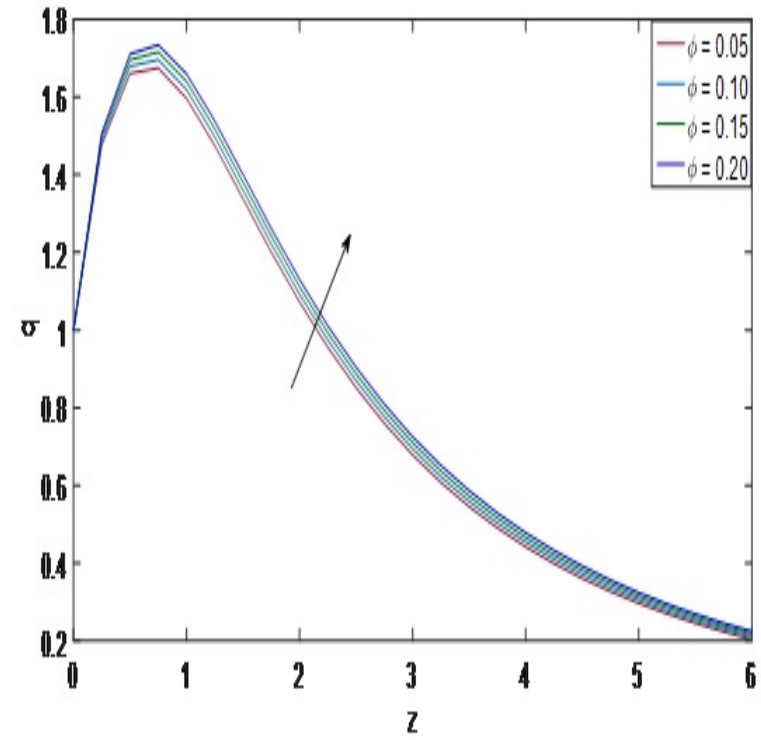

Fig. 2 The velocity profiles for $\mathrm{q}$ against $\phi$

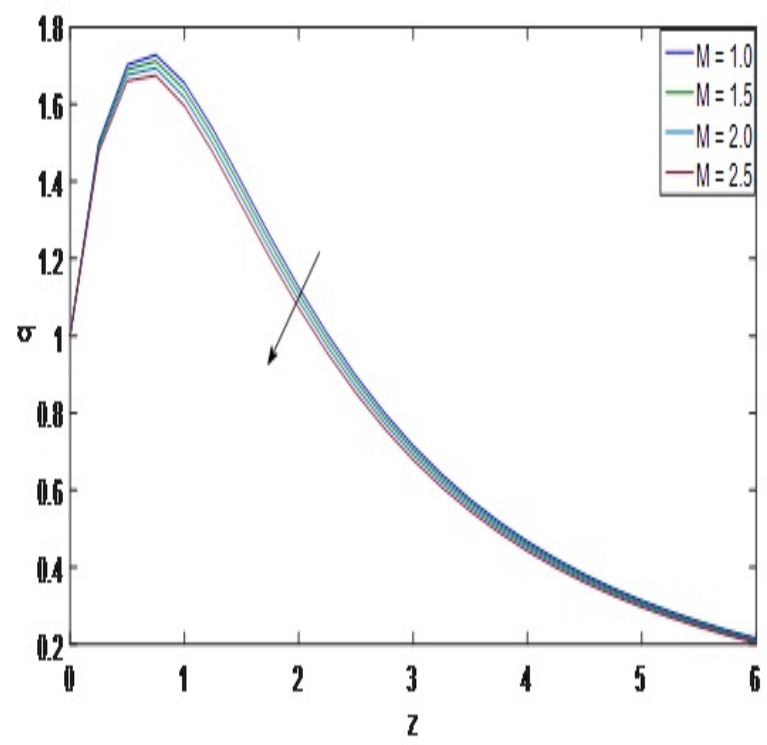

Fig. 3 The velocity profiles for $\mathrm{q}$ against $\mathrm{M}$

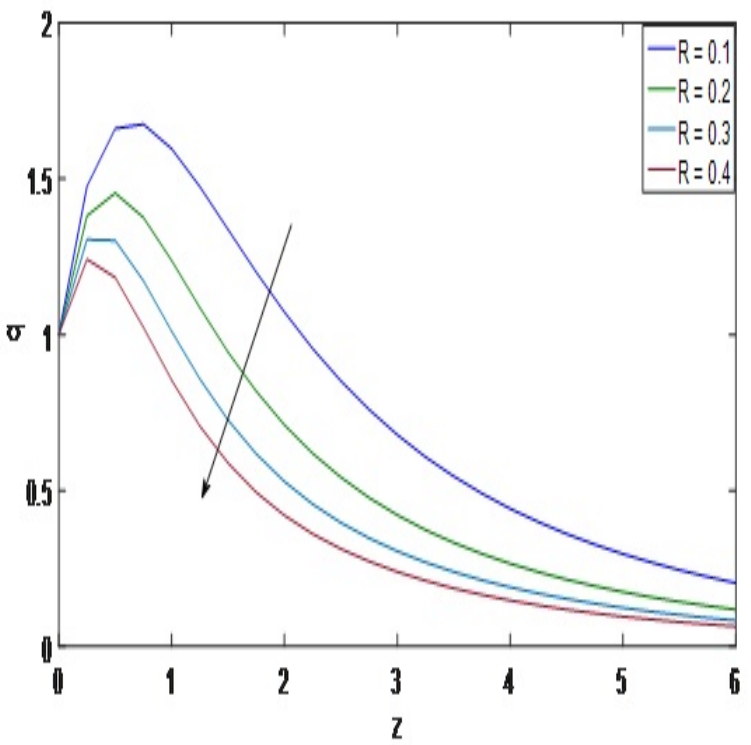

Fig. 4 The velocity profiles for $\mathrm{q}$ against $\mathrm{R}$ 


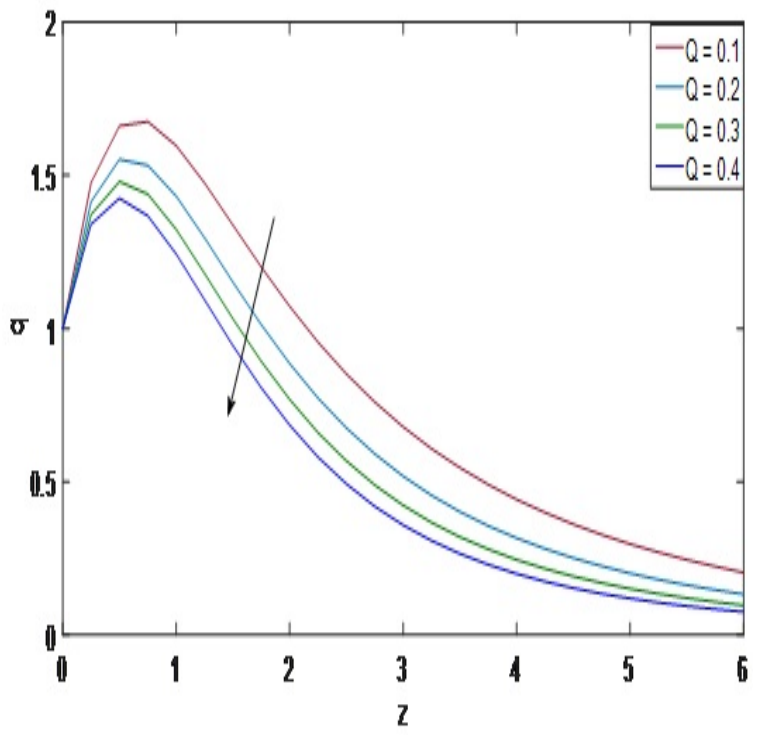

Fig. 5 The velocity profiles for q against Q

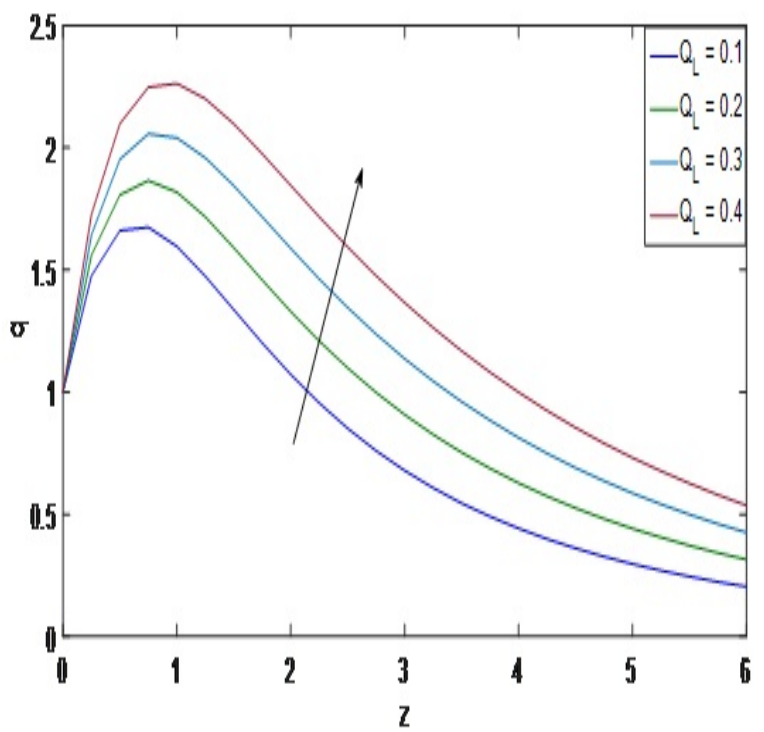

Fig. 6 The velocity profiles for q against $\mathrm{Q}_{\mathrm{L}}$.

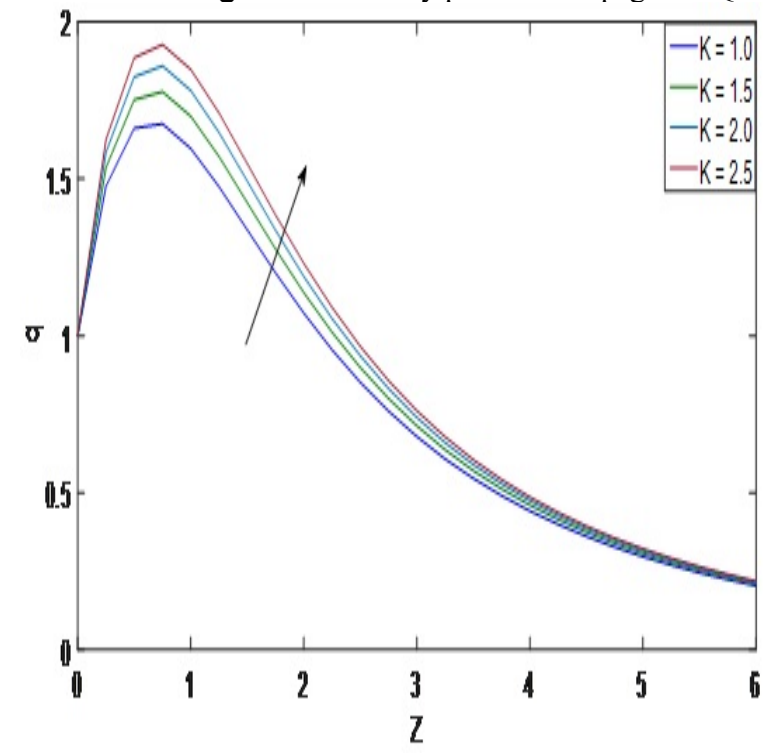

Fig. 7 The velocity profiles for q against K.

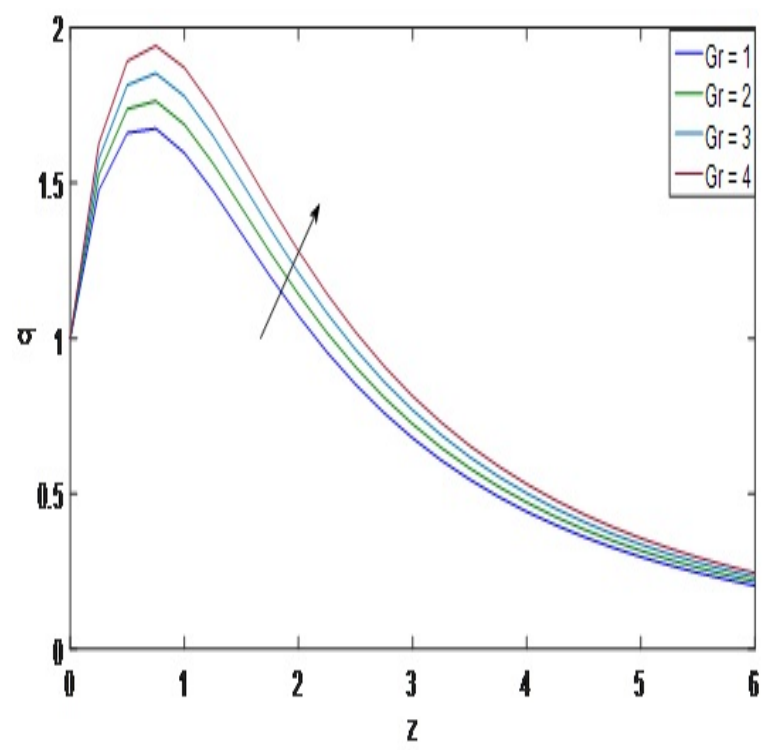

Fig. 8 The velocity profiles for q against Gr.

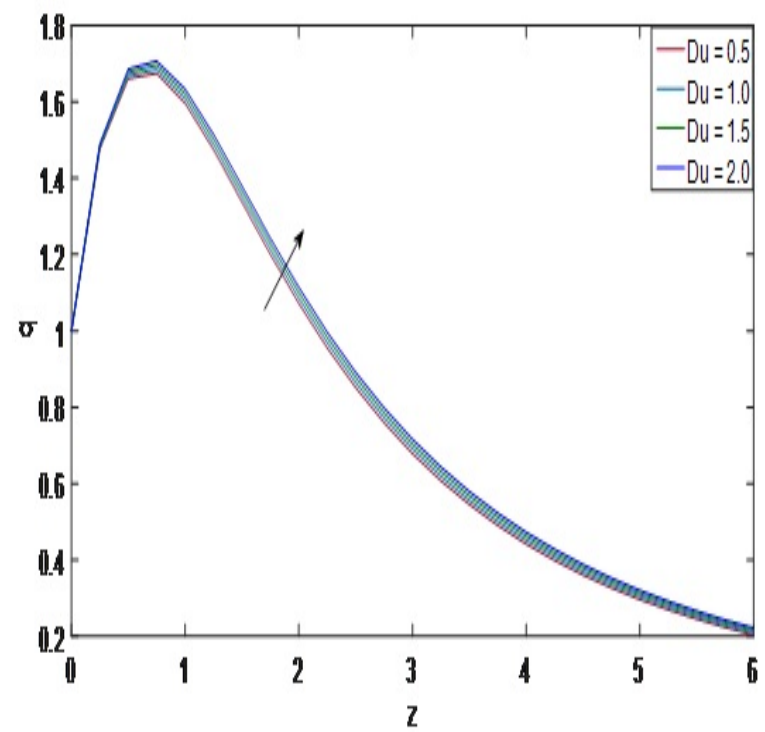

Fig. 9 The velocity profiles for q against Du.

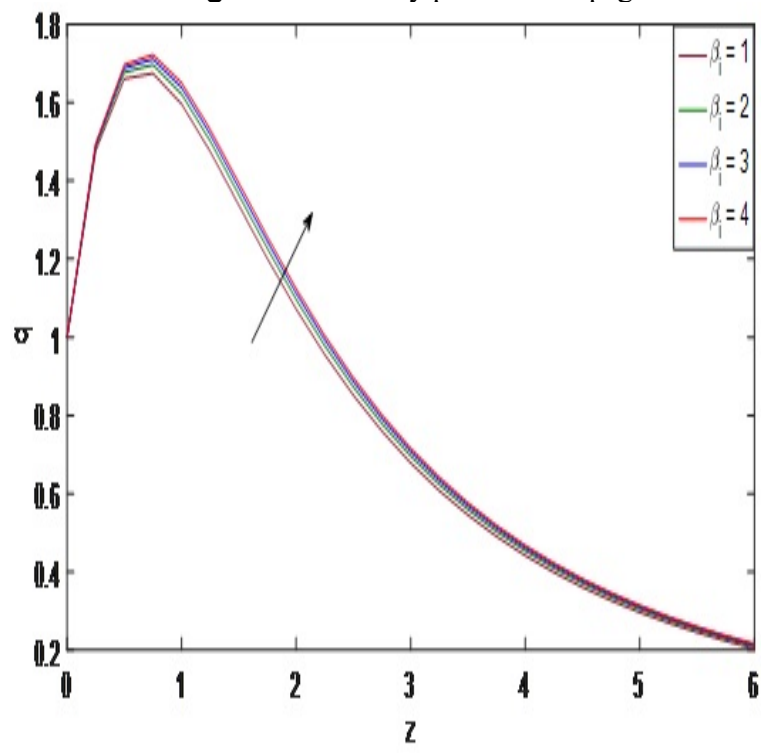

Fig. 10 The velocity profiles for q against $\beta_{\mathrm{i}}$. 


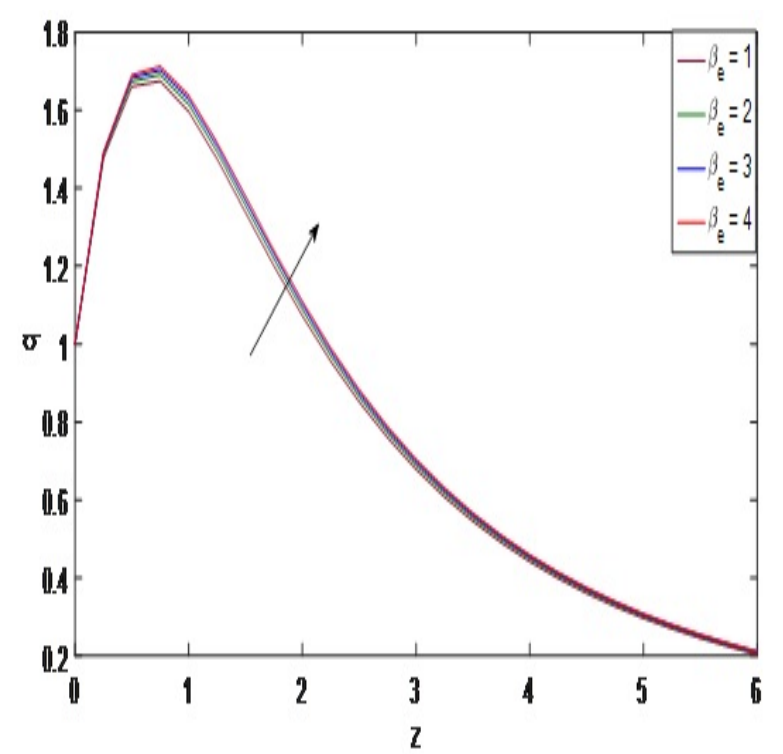

Fig. 11 The velocity profiles for q against $\beta_{\mathrm{e}}$.

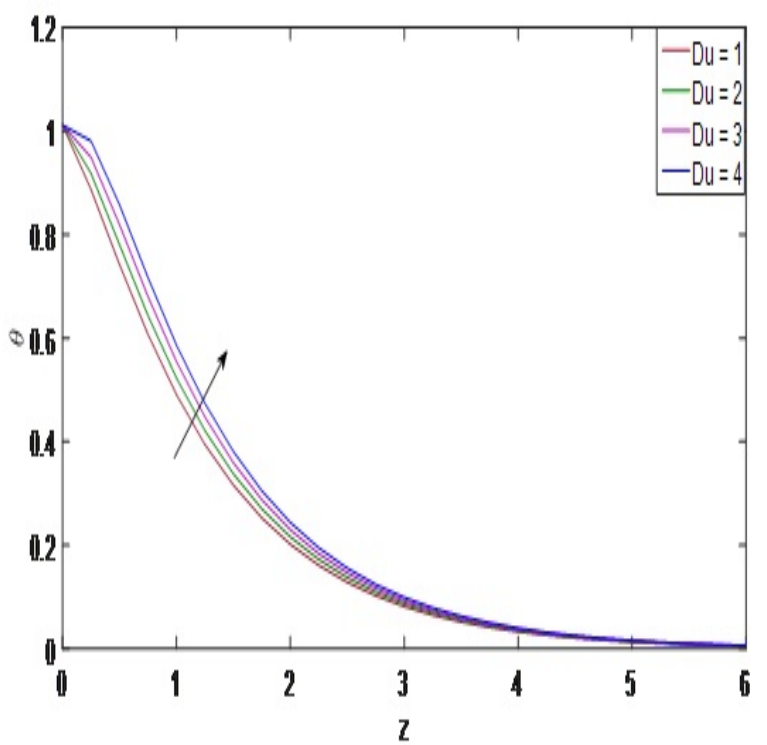

Fig. 12 The temperature profiles for $\theta$ against $\mathrm{Du}$.

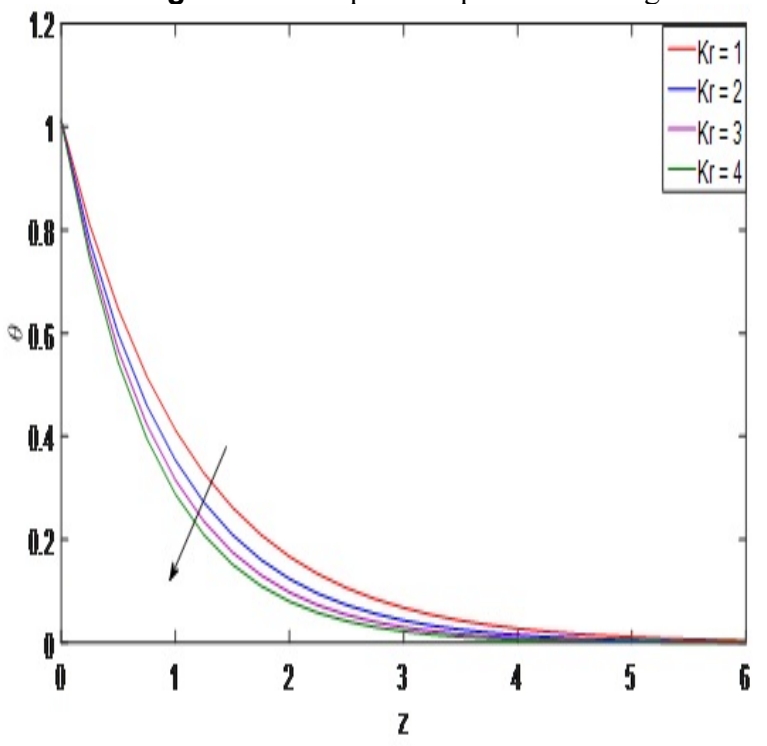

Fig. 13 The temperature profiles for $\theta$ against $\mathrm{Kr}$.

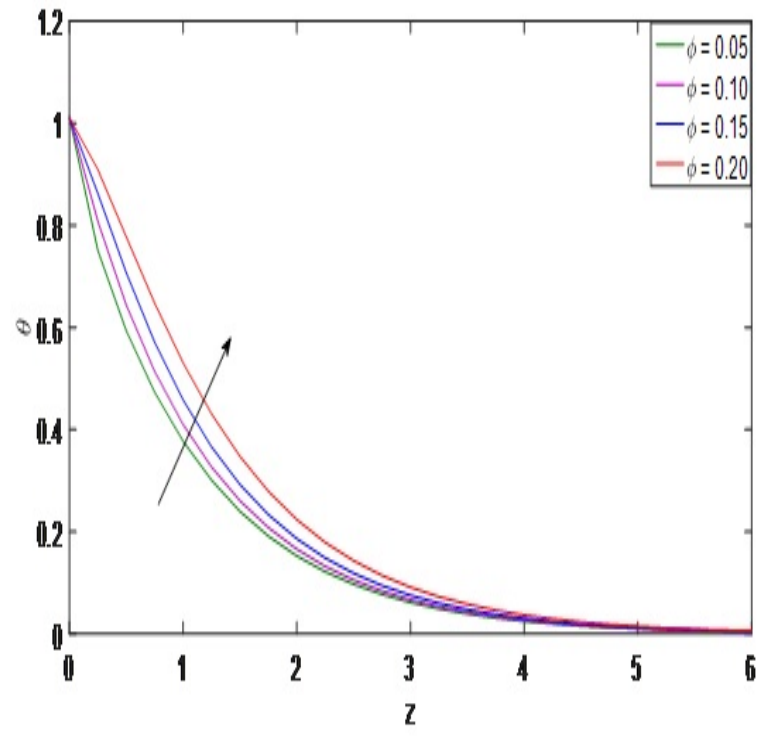

Fig. 14 The temperature profiles for $\theta$ against $\phi$.

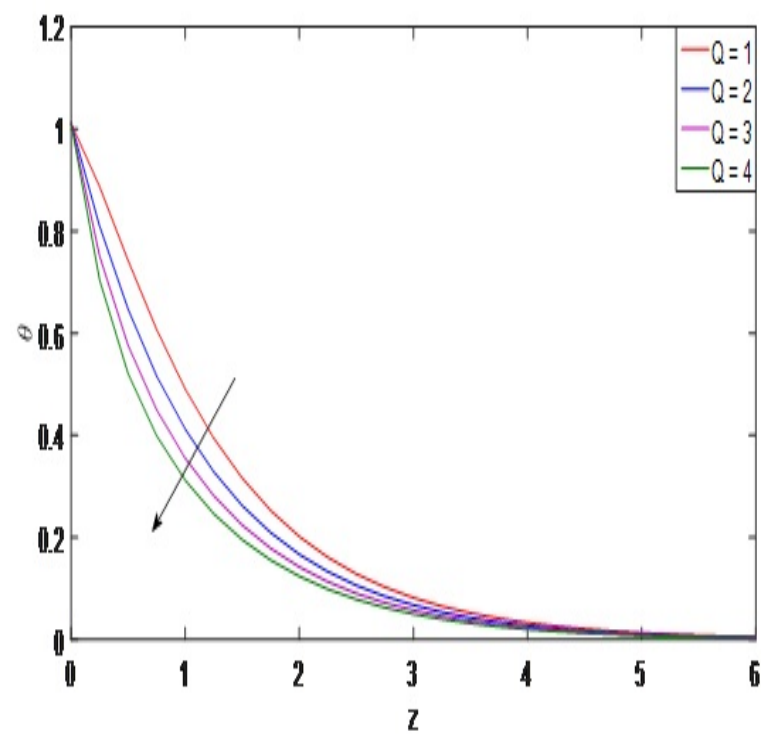

Fig. 15 The temperature profiles for $\theta$ against $\mathrm{Q}$.

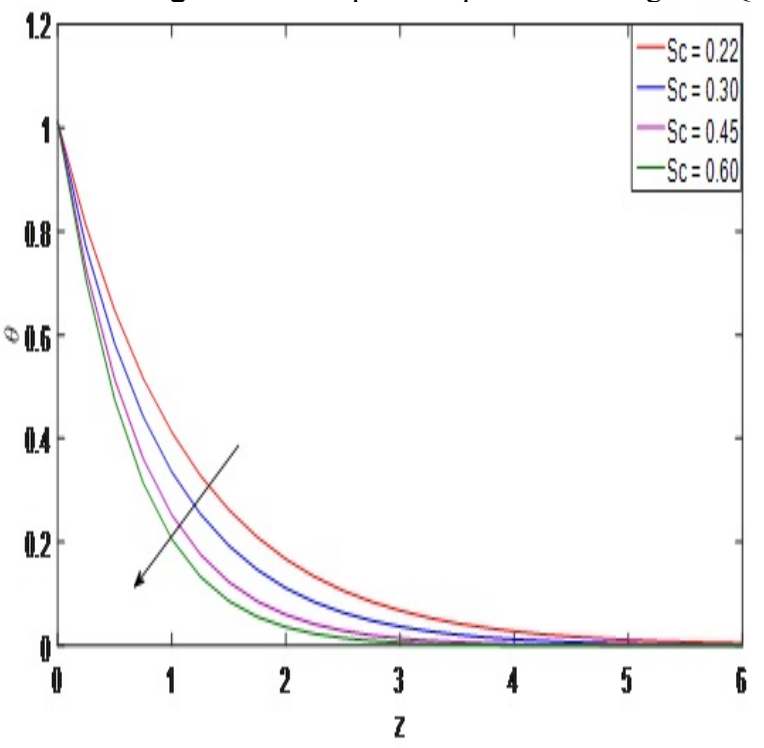

Fig. 16 The temperature profiles for $\theta$ against Sc. 


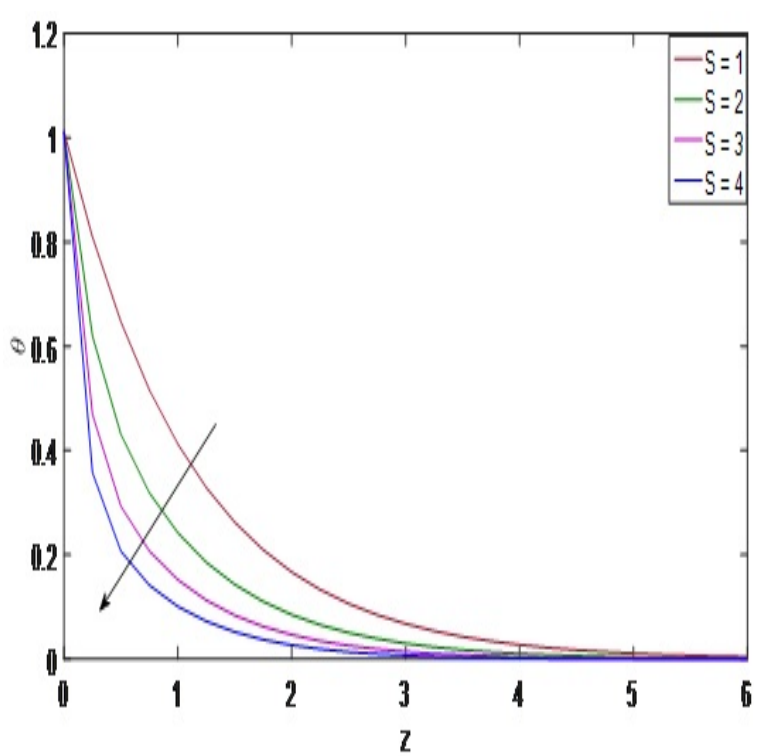

Fig. 17 The temperature profiles for $\theta$ against $\mathrm{S}$.

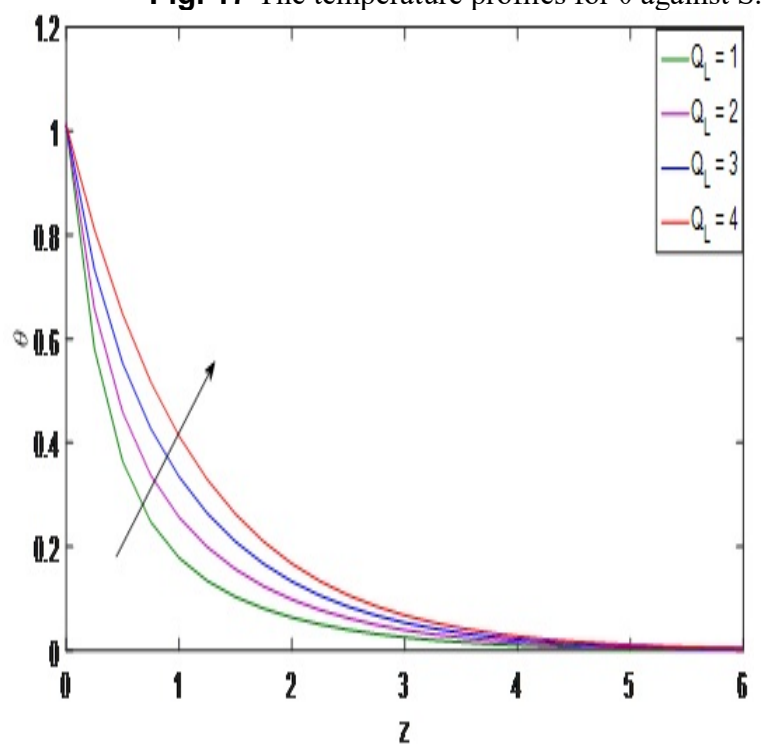

Fig. 18 The temperature profiles for $\theta$ against $\mathrm{Q}_{\mathrm{L}}$.

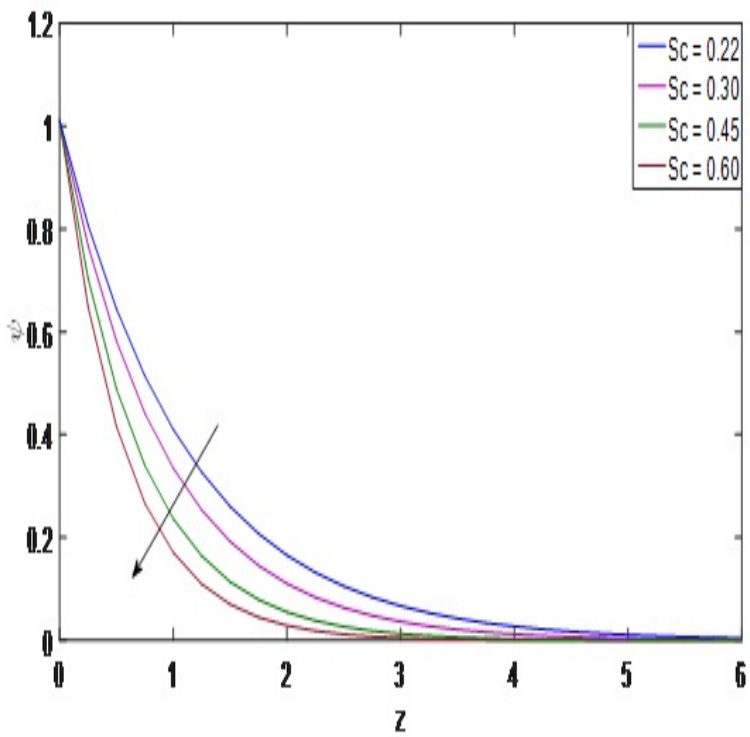

Fig. 19 The concentration profiles for $\psi$ against Sc.

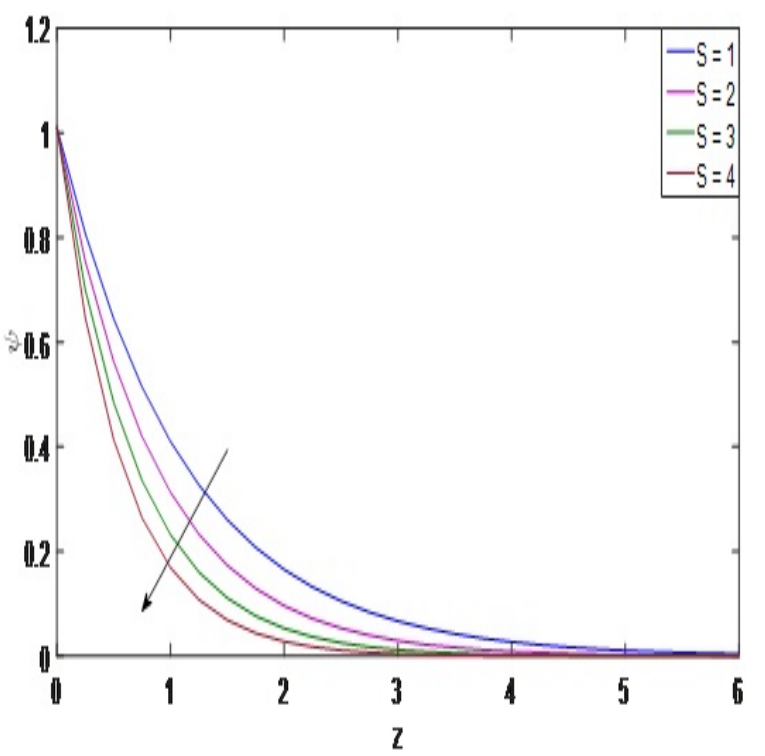

Fig. 20 The concentration profiles for $\psi$ against $\mathrm{S}$.

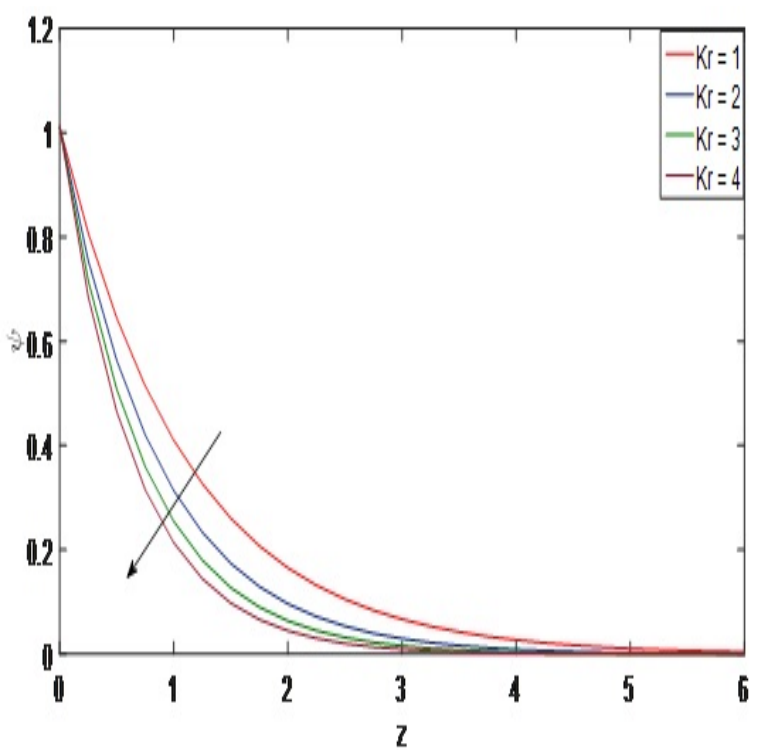

Fig. 21 The concentration profiles for $\psi$ against $\mathrm{Kr}$.

thickness increases as the Dufour number increases. It is observed that, with increasing ion slip parameter $\beta i$ the velocity $q$ increases. From figure 10 , the effective conductivity increases as increase in $\beta i$, hence the damping force on the dimensionless velocity is decreasing due to this the dimensionless velocity increases. We noticed from Fig. 11, with the increase in Hall parameter $\beta \mathrm{e}$ the velocity q increases in entire fluid region. Hence, the resultant velocity increases with a raise in the Hall parameter. The inclusion of Hall parameter reduces the effective conductivity and hence drops the magnetic resistive force.

Fig. 12 depicted that the temperature profiles against parameters Du. Du causes to augment the thermal boundary layer thickness. An increasing of Du Physically retards the influence of species gradients on the temperature, and temperature is raised and the boundary layer thickness is heated. The influence of the chemical reaction parameter $\mathrm{Kr}$ on the nanofluid temperature profiles, for the Ag-water based nanofluid particles with $\phi=0.15$, is illustrated in Fig. 13. It is observed that an increase in $\mathrm{Kr}$ contributes to the decrease in the nanofluid temperature distributions. Fig. 16 shows the nanofluid temperature profiles for different values of Schmidt number Sc. It is noticed that the effect of increasing values of Sc results in a decreasing the nanofluid temperature distribution. Fig. 19 displays the effects of the Schmidt number on the species concentration profiles. As the Schmidt number 
increases the species concentration, the solutal boundary layer thickness decreases. The Fig. 20 depicted that the concentration profiles against suction parameter $\mathrm{S}$. As the $\mathrm{S}$ increases, the species concentration decreases. This is due to the usual fact that the suction stabilizes the boundary growth. These consequences are obviously supported from the physical point of view. From Figure 21, it is seen that the concentration is reduced as an increase in $\mathrm{Kr}$. The chemical reaction parameter is to decrease in the chemical molecular diffusivity.

Table 1 Comparison of skin-friction coefficient values for different

\begin{tabular}{|c|c|c|c|c|c|c|c|c|c|}
\hline$\beta_{\mathrm{e}}$ & $\beta_{i}$ & $\mathbf{M}$ & $\mathbf{K}$ & $\mathbf{R}$ & $\mathbf{S}$ & $O_{1}$ & $\mathbf{K r}$ & $\phi$ & $C_{f}$ \\
\hline $\begin{array}{l}0.2 \\
0.4 \\
0.6 \\
0.8\end{array}$ & & & & & & & & & $\begin{array}{l}1.1208 \\
1.0322 \\
0.9292 \\
0.8251\end{array}$ \\
\hline & $\begin{array}{l}0.1 \\
0.3 \\
0.5 \\
0.7\end{array}$ & & & & & & & & $\begin{array}{l}0.7544 \\
0.6992 \\
0.6441 \\
0.5914\end{array}$ \\
\hline & & $\begin{array}{l}1.0 \\
1.5 \\
2.0 \\
2.5\end{array}$ & & & & & & & $\begin{array}{l}0.0132 \\
0.3562 \\
0.7270 \\
1.9083\end{array}$ \\
\hline & & & $\begin{array}{l}0.1 \\
0.2 \\
0.3 \\
0.4\end{array}$ & & & & & & $\begin{array}{l}2.9615 \\
1.9725 \\
1.5354 \\
1.2803\end{array}$ \\
\hline & & & & $\begin{array}{l}0.2 \\
0.4 \\
0.6 \\
0.8\end{array}$ & & & & & $\begin{array}{l}0.7572 \\
0.8217 \\
0.8894 \\
0.9583\end{array}$ \\
\hline & & & & & $\begin{array}{l}0.2 \\
0.4 \\
0.6 \\
0.8\end{array}$ & & & & $\begin{array}{l}0.8769 \\
1.1914 \\
1.4959 \\
1.7916\end{array}$ \\
\hline & & & & & & $\begin{array}{l}0.2 \\
0.4 \\
0.6 \\
0.8\end{array}$ & & & $\begin{array}{l}0.6636 \\
0.5368 \\
0.4099 \\
0.2831\end{array}$ \\
\hline & & & & & & & $\begin{array}{l}0.2 \\
0.4 \\
0.6 \\
0.8\end{array}$ & & $\begin{array}{l}0.7337 \\
0.7360 \\
0.7378 \\
0.7387\end{array}$ \\
\hline & & & & & & & & $\begin{array}{l}0.02 \\
0.04 \\
0.06 \\
0.08\end{array}$ & $\begin{array}{l}1.2682 \\
1.1722 \\
1.0806 \\
0.9935\end{array}$ \\
\hline
\end{tabular}

In Tables 1 and 2, the numerical values of the Skin-friction and Nusselt number for the nano-particles Ag are presented and in Table 3, Sherwood numbers are presented. From Table 1, the skin friction increases with the increasing values of $\mathrm{M}, \mathrm{R}, \mathrm{S}, \mathrm{Kr}$ and reduces with $\beta \mathrm{e}$, $\beta i, K, Q L$ and $\phi$ for the nano-particles Ag. From Table 2, the Nusselt number increases with $\mathrm{S}$ and $\mathrm{Q}$ and decreases with QL, Du and $\phi$ for the Ag-nano-particles. It is clear that From Table 3 the Sherwood number increases with the increasing values of S, SC and Kr. Table 4 contains thermal properties of nanofluid.

\section{CONCLUSIONS}

In the present study, we have theoretically studied the effects of diffusion-thermo, radiation-absorption and Hall and ion slip effects on MHD free convective rotating flow of the metallic nanoparticles past a moving infinite vertical porous plate with constant heat source. The set of governing equations are solved analytically by using perturbation
Table 2 Comparison of rate of heat transfer values for different quantities

\begin{tabular}{|c|c|c|c|c|c|}
\hline $\mathbf{S}$ & $\mathbf{Q}_{\mathbf{L}}$ & $\mathbf{D u}$ & $\boldsymbol{\phi}$ & $\mathbf{Q}$ & $\mathbf{N u}$ \\
\hline 1.0 & & & & & 1.0482 \\
1.2 & & & & & 1.6491 \\
1.4 & & & & & 2.2532 \\
1.6 & & & & & 2.8557 \\
\hline & 0.5 & & & & 2.3130 \\
& 1.0 & & & & 2.1724 \\
& 1.5 & & & & 2.0319 \\
& 2.0 & & & & 1.8914 \\
\hline & & 0.2 & & & 1.7569 \\
& & 0.4 & & & 1.5797 \\
& & 0.6 & & & 1.4025 \\
& & 0.8 & & & 1.2254 \\
\hline & & & 0.02 & & 1.9660 \\
& & & 0.04 & & 1.7863 \\
& & & 0.06 & & 1.6228 \\
& & & 0.08 & & 1.4739 \\
\hline & & & & 0.1 & 0.7143 \\
& & & & 0.2 & 0.7545 \\
& & & & 0.3 & 0.7937 \\
& & & & 0.4 & 0.8322 \\
\hline
\end{tabular}

Table 3 Comparison of rate of mass transfer values for different quantities

\begin{tabular}{|c|c|c|c|}
\hline Sc & S & Kr & Sh \\
\hline 0.22 & & & 0.9103 \\
0.30 & & & 1.1141 \\
0.45 & & & 1.4651 \\
0.60 & & & 1.7924 \\
\hline & 0.1 & & 1.1678 \\
& 0.2 & & 1.2309 \\
& 0.3 & & 1.2956 \\
& 0.4 & & 1.3620 \\
\hline & & 0.1 & 1.1602 \\
& & 0.2 & 1.2612 \\
& & 0.3 & 1.3486 \\
& & 0.4 & 1.4268 \\
\hline
\end{tabular}

Table 4 Thermo physical properties - (Veera Krishna and hamkha2019)

\begin{tabular}{|c|c|c|c|c|}
\hline & $\boldsymbol{\rho}$ & $\mathbf{C p}$ & $\mathbf{K}$ & $\boldsymbol{\beta x 1 0}^{-5}$ \\
\hline WATER & 997.1 & 4179 & 0.613 & 21 \\
\hline AG & 10,500 & 235 & 429 & 1.89 \\
\hline
\end{tabular}

technique. The effects of various fluid flow parameters on velocity, temperature and species concentration, Skin-friction and the rate of heat transfer coefficient are derived and discussed through graphs and tables. The following conclusions are made from the present investigation:

$>$ In the boundary layer region, fluid velocity decreases with the increasing values of rotation parameter, magnetic field parameter and suction parameter while it increases with the increasing values of Hall and ion slip parameters, Dufour number and radiation absorption parameter.

$>$ An increase in the Dufour number and radiation absorption parameter leads to increase the thermal boundary layer thickness.

$>$ The species concentration decreases with the increasing values of suction parameter, chemical reaction parameter and Schmidt number.

$>$ The skin friction coefficient decreases with the increasing Hall and ion slip parameter, permeability parameter and Radiation absorption parameter. 
$>$ Nusselt number decreases with radiation absorption parameter and Dufour parameter.

$>$ Sherwood number increases with suction parameter and chemical reaction parameter.

\section{NOMENCLATURE}

$\begin{array}{ll}\mathrm{Nu} & \text { Nusselt number } \\ \mathrm{Sh} & \text { Sherwood number } \\ \mathrm{e} & \text { Electron charge } \\ \mathrm{Pe} & \text { Electron pressure } \\ \mathrm{B} & \text { Magnetic induction vector } \\ \mathrm{Jx}, \mathrm{Jy} & \text { Current densities along } \mathrm{x} \text { and y directions } \\ \mathrm{E} & \text { Electric field } \\ \mathrm{u}, \mathrm{v}, \mathrm{w} & \text { velocity components along } \mathrm{x}, \mathrm{y} \text { and } \mathrm{z} \text { axes } \\ B_{0} & \text { Applied magnetic field } \\ \mathrm{Cp} & \text { Specific heat } \\ \mathrm{q} & \text { complex velocity } \\ \mathrm{t} & \text { time } \\ \mathrm{Tw} & \text { Wall temperature } \\ T_{\infty} & \text { Temperature of the ambient nanofluid } \\ U_{0} & \text { Characteristic velocity } \\ W_{0} & \text { Mass flux velocity } \\ C_{\infty} & \text { Concentration in the free stream } \\ \mathrm{g} & \text { acceleration due to gravity } \\ \mathrm{k} & \text { permeability of porous medium } \\ \mathrm{T} & \text { temperature of the nanofluid } \\ \mathrm{Q} & \text { heat source parameter } \\ \mathrm{Knf} & \text { thermal conductivity of the nanofluid } \\ \mathrm{Ks} & \text { thermal conductivity of the solid } \\ \mathrm{Q}^{*} & \text { additional heat source } \\ \mathrm{R} & \text { Rotation parameter } \\ \mathrm{S} & \text { suction (S }>0 \text { ) or injection }(\mathrm{S}<0) \text { parameter } \\ \mathrm{Q} \mathrm{L} & \text { radiation absorption parameter } \\ \mathrm{K} & \text { permeability parameter } \\ \mathrm{Du} & \text { diffusion-thermo parameter } \\ & \end{array}$

Greek symbols

$\begin{array}{ll}\beta_{n f} & \begin{array}{l}\text { coefficient of thermal expansion of nanofluid } \\ \sigma\end{array} \\ \sigma_{n f} & \begin{array}{l}\text { electrical conductivity of the base fluid } \\ \text { density of the nanofluid }\end{array} \\ \rho_{n f} & \text { viscosity of the nanofluid } \\ \mu_{n f} & \text { solid volume fraction of the nanoparticles } \\ \phi & \text { coefficient of thermal expansion of the fluid } \\ \beta_{\mathrm{f}} & \text { coefficient of mass expansion of the solid } \\ \beta_{\mathrm{C}} & \text { density of the fluid } \\ \rho_{f} & \text { thermal diffusivity of the nanofluid } \\ \alpha_{n f} & \text { constant angular velocity } \\ \Omega & \end{array}$

Subscripts

$\begin{array}{ll}\mathrm{f} & \text { Fluid } \\ \mathrm{s} & \text { Solid } \\ \mathrm{nf} & \text { Nanofluid }\end{array}$

\section{REFERENCES}

Abbasi, F.M., Hayat, T., and Alsaadi. F., 2015, "Hydromagnetic peristaltic transport of water-based nanofluids with slip effects through an asymmetric channel", Int J Mod Phys B, 29, 1-17.

Alsaedi, M. Awais and Hayat, T., 2012, "Effect of Heat Generation/Absorption on Stagnation Point Flow of Nanofluid over a Surface with Convective Boundary Conditions," Communications in Nonlinear Science and Numerical Simulation, 17, 4210-4223.

http://dx.doi.org/10.1016/j.cnsns.2012.03.008
Abdullah, A.A.A., Al-Rashed., LiouaKolsi, D., Kalidasan, K., Maatki., CH., Naceur Borjini, Md., Aichouni, Md., and Rajesh Kanna, P., 2017, "Effect of Magnetic Field Inclination on Magnetoconvective Induced Irreversibilities in a CNT-Water Nanofluid Filled Cubic Cavity," Frontiers in Heat and Mass Transfer, 8, 31, 1-10. http://dx.doi.org/10.5098/Hmt.8.31

Arifuzzaman, S. M., Khan, M. S., Islamc, M. S., Islam, M. M., Rana, B. M. J., Biswas, P., and Ahmmed, S. F., 2017, "MHD Maxwell Fluid Flow in Presence of Nano-Particle Through a Vertical Porous-Plate with Heat-Generation, Radiation Absorption and Chemical Reaction," Frontiers in Heat and Mass Transfer, 9, 25, 1-14. http://dx.doi.org/10.5098/Hmt.9.25

Ananda Reddy, N., Chandra Reddy, P., Raju, M.C., and Varma, S.V.K., 2018, "Radiation and Dufour Effects on Laminar Flow of a Rotating Fluid Past a Porous Plate in Conducting Field," Frontiers In Heat And Mass Transfer, 10, 4, 1-7. http://dx.doi.org/10.5098/Hmt.10.4

Buongiorno, J., 2006, "Convective Transport in Nanofluids," ASME Journal of Heat Transfer, 128, 240-250.

http://dx.doi.org/10.1115/1.2150834

Choi, S.U.S., 1995, "Enhancing Thermal Conductivity of Fluids with Nanoparticles," In: Proceedings of the ASME International Mechanical Engineering Congress and Exposition, San Francisco, USA. ASME, FED 231/MD, 66, 99-105.

Das, S., and Jana, R.N., 2015, "Natural Convective Magneto-Nanofluid Flow and Radiative Heat Transfer Past a Moving Vertical Plate," Alexandria Engineering Journal, 54, 55-64 http://dx.doi.org/10.1016/j.aej.2015.01.001

Das, S., Jana, R.N., and Makinde, O.D., 2016, “Transient Natural Convection in a Vertical Channel Filled with Nanofluids in the Presence of Thermal Radiation," Alexandria Engineering Journal, 55, 253-262

http://dx.doi.org/10.1016/j.aej.2015.10.013

Dharmaiah, G., Balamurugan, K.S., and Venkateswarulu, M., 2017, "Analysis of Heat and Mass Transfer on MHD Flow of Nanofluid over a Semi Infinite Moving Surface with Diffusion Thermo", SKIT Journal, 7 (2), 79-86.

Dharmaiah, G., Vedavathi, N., Baby Rani, CH., and Balamurugan, K.S., 2018, "MHD Boundary Layer Flow and Heat Transfer af a Nanofluid past a Radiative and Impulsive Vertical Plate", Frontiers in Heat and Mass Transfer (FHMT), 11, 14, 1-7.

http://dx.doi.org/10.5098/hmt.11.14

Dharmaiah, G., Chamkha, A.J., Vedavathi, N., and Balamurugan, K.S., 2019, "Viscous Dissipation Effect on Transient Aligned Magnetic Free Convective Flow Past an Inclined Moving Plate," Frontiers In Heat And Mass Transfer, 12, 17, 1-11.

http://dx.doi.org/10.5098/Hmt.12.17

Dharmaiah, G., Baby Rani, CH., Vedavathi, N., and Balamurugan, K.S., 2018, "Heat and Mass Transfer on MHD Fluid Flow over a Semi Infinite Flat Plate with Radiation Absorption, Heat Source and Diffusion Thermo Effect," Frontiers In Heat And Mass Transfer, 11, 6, $1-8$.

http://dx.doi.org/10.5098/Hmt.11.6

Hamad, M.A.A., and Ferdows, M., 2012, "Similarity Solutions to Viscous Flow and Heat Transfer of Nanofluid over Non-Linearly Stretching Sheet," Applied Mathematics and Mechanics English Edition, 33(7), 923-930. 


\section{http://dx.doi.org/10.1007/s10483-012-1595-7}

Hamad, M.A.A., and Pop, I., 2011, "Unsteady MHD Free Convection Flow Past a Vertical Permeable Flat Plate in a Rotating Frame of Reference with Constant Heat Source in a Nanofluid," Heat Mass Transfer, 47, 1517-1524.

http://dx.doi.org/10.1007/s00231-011-0816-6

Habib-OlahSayehvand, Shirley Abelman, and Amir BasiriParsa, 2017, "MHD Nanofluid Flow with Viscous Dissipation and Joule Heating Through a Permeable Channel," Frontiers in Heat and Mass Transfer, 9, 30, 1-9.

http://dx.doi.org/10.5098/Hmt.9.30

Hong Hu., and Chung, J. N., 2018, “A Molecular Dynamics Simulation of Nanoscale Water Vapor Absorption on the Surface of Libraqueous Solution," Frontiers In Heat And Mass Transfer, 11, 24, 1-8.

http://dx.doi.org/10.5098/Hmt.11.24.

Kumaresan, E., Vijaya Kumar, A .G. and Prakash, J., 2018, “Analytical Investigations of Diffusion Thermo Effects on Unsteady Free Convection Flow Past an Accelerated Vertical Plate," Frontiers in Heat and Mass Transfer, 10, 2, 1-9.

http://dx.doi.org/10.5098/Hmt.10.2

Mahantesh, M.N., and Shakunthala, S., 2017, "Flow and Heat Transfer of Carbon Nanofluids over a Vertical Plate," Frontiers in Heat and Mass Transfer, 9, 27, 1-10.

http://dx.doi.org/10.5098/Hmt.9.27

Maouassi, A., Baghidja,A., Douad, S., and Zeraibi, N., 2018, "Heat Exchanges Intensification Through a Flat Plat Solar Collector by Using Nanofluids as Working Fluid," Frontiers In Heat And Mass Transfer, 10, 35, 1-7.

http://dx.doi.org/10.5098/Hmt.10.35

Mahanthesh, B., Gireesha, B.J., and Rama Subba Reddy, G., 2016, "Heat and Mass Transfer Effects on the Mixed Convective Flow of Chemically Reacting Nanofluid Past A Moving/stationary Vertical Plate," Alexandria Engineering Journal.

http://dx.doi.org/10.1016/j.aej.2016.01.022

Bachok, N., Ishak, A., and Pop, I., 2012, "Boundary Layer Flow Over A Moving Surface in A Nanofluid with Suction or Injection," Acta Mech Sin., 28(1), 34-40.

http://dx.doi.org/10.1007/s10409-012-0014-x

Oyelakin, I.S., Mondala, Y, S., and Sibanda, P., 2017, “Unsteady MHD Three-Dimensional Casson Nanofluid Flow over a Porous Linear Stretching Sheet With Slip Condition," Frontiers in Heat and Mass Transfer, $\mathbf{8}, 37,1-9$.

http://dx.doi.org/10.5098/Hmt.8.37

Ramprasad, J.L., Balamurugan K.S., and Dharmaiah, G., 2019, “A Study on $\mathrm{Al}_{2} \mathrm{O}_{3}-\mathrm{H}_{2} \mathrm{O}$ Nanofluid in the presence of Constant heat source", International Journal of Mechanical and Production Engineering Research and Development (IJMPERD), 9 (2), 399-406.

Rana, and Bharava, R., 2012, "Flow and Heat Transfer of a Nanofluid over a Nonlinearly Stretching Sheet," Communications in Nonlinear Simulation, 7, 212-226.

http://dx.doi.org/10.1016/j.cnsns.2011.05.009

Rashad, A.M., Chamkha, A.J., Mallikarjuna, B., and Abdou, M.M.M., 2018, "Mixed Bioconvection Flow of a Nanofluid Containing Gyrotactic Microorganisms Past a Vertical Slender Cylinder," Frontiers in Heat and Mass Transfer, 10, 21, 1-8.
http://dx.doi.org/10.5098/Hmt.10.21

Ramesh, G.K., and Gireesha, B.J., 2017, "Non-Linear Radiative Flow of Nanofluid past a Moving/Stationary Riga Plate," Frontiers in Heat and Mass Transfer, 9, 3, 1-7.

http://dx.doi.org/10.5098/Hmt.9.3

Srinivasacharya, D., and Shafeeurrahaman, Md., 2017, "Mixed Convection Flow of Nanofluid in a Vertical Channel with Hall and IonSlip Effects", Frontiers in Heat and Mass Transfer, 8, 11, 1-8. http://dx.doi.org/10.5098/Hmt.8.11

Sathish Kumar, M., Sandeep, N., and Rushi Kumar, B., 2017, "Free Convective Heat Transfer of MHD Dissipative Carreau Nanofluid Flow over a Stretching Sheet", Frontiers in Heat and Mass Transfer, 8, 13, 18.

http://dx.doi.org/10.5098/Hmt.8.13

Stanford Shateyi., 2017, "Heat and Mass Transfer for Natural Convection MHD Flow Over a Permeable Moving Vertical Plate with Convective Boundary Condition in the Presence of Viscous Dissipation," Frontiers in Heat and Mass Transfer, 9, 7, 1-6. http://dx.doi.org/10.5098/Hmt.9.7

Seth, G.S., Bhattacharyya, A., and Tripathi, R., 2017, "Effect of Hall Current on MHD Natural Convection Heat and Mass Transfer Flow of Rotating Fluid past a Vertical Plate with Ramped Wall Temperature," Frontiers in Heat and Mass Transfer, 9, 21, 1-12. http://dx.doi.org/10.5098/Hmt.9.21

Samrat, S.P., Sulochana, C., and Ashwinkumar, G.P., 2018, "Impact of Thermal Radiation and Chemical Reaction on Unsteady 2d Flow of Magnetic-Nanofluids over an Elongated Plate Embedded with Ferrous Nanoparticles," Frontiers In Heat And Mass Transfer, 10, 31, 1-8. http://dx.doi.org/10.5098/Hmt.10.31.

Satya Narayana, P.V., Venkateswarlu, B., and Venkataramana, S., 2015, "Thermal Radiation and Heat Source Effects on MHD Nanofluid Past a Vertical Plate in a Rotating System with Porous Medium. Heat Transfer-Asian Research, 44 (1), 1-19

http://dx.doi.org/10.1002/htj.21101

Srinivasacharya, D., and Shafeeurrahman, Md., 2017, "Hall and ion slip effects on mixed convection flow of nanofluid between two concentric cylinders", J Assoc Arab Univ Basic Appl Sci, 24 (1), 223-31. https://doi.org/10.1016/j.jaubas.2017.03.002.

Sutton, G., and Sherman, A., 1965, "Engineering magnetohydrodynamics", New York: Mc Graw Hill.

Tiwari, R.K., and Das, M.D., 2007, "Heat Transfer Augmentation in a Two-Sided Lid-Driven Differentially Heated Square Cavity Utilizing Nanofluids," International Journal of Heat and Mass Transfer, 50 2002-2018.

http://dx.doi.org/10.1016/j.ijheatmasstransfer.2006.09.034

Turkyilmazoglu, M., 2014, "Exact Analytical Solutions for Heat and Mass Transfer of MHD Slip Flow in Nanofluids. Chemical Engineering Science, 84, 182-187.

http://dx.doi.org/10.1016/j.ces.2012.08.029

Tashkandi, Md. A., Abdelkarim Aydi, 2018, "Heat Transfer Intensification in a 3d Cavity Using Hybrid Cnt-Al2o3 (15-85\%) Nanofluid," Frontiers In Heat And Mass Transfer, 11, 27, 1-6. http://dx.doi.org/10.5098/Hmt.11.27 
Veeresh, C., Varma, S. V. K., Vijaya Kumar, A .G., Umamaheswar, M., and Raju, M. C., 2017, "Joule Heating and Thermal Diffusion Effects on MHD Radiative and Convective Casson Fluid Flow past an Oscillating Semi-Infinite Vertical Porous Plate," Frontiers in Heat and Mass Transfer, 8, 1, 1-8.

http://dx.doi.org/10.5098/Hmt.8.1

Vedavathi, N., Dharmaiah, G., Balamurugan K.S., and Prakash, J., 2017, "Heat Transfer on MHD Nanofluid Flow over a Semi Infinite Flat Plate Embedded in a Porous Medium With Radiation Absorption, Heat Source and Diffusion Thermo Effect", Frontiers in Heat and Mass Transfer (FHMT), 9, 38, 1-8.

http://dx.doi.org/10.5098/hmt.9.38

Vedavathi, N., Dharmaiah, G., Balamurugan, K.S., and Ramakrishna, K., 2019, "A Study on MHD Boundary Layer Flow Rotating Frame Nanofluid with Chemical Reaction", Frontiers in Heat and Mass Transfer (FHMT), 12, 10, 1-9.

http://dx.doi.org/10.5098/hmt.12.10

Veera Krishna, M., and Chamkha, A.J., 2019, "Hall and ion slip effects on MHD rotating boundary flow of nanofluid past an infinite vertical plate embedded in a porous medium", Results in Physics, 15, 1-10. https://doi.org/10.1016/j.rinp.2019.102652
Venkateswarlu, B., and Satya Narayana, P.V., 2015, "Chemical Reaction and Radiation Absorption Effects on the Flow and Heat Transfer of a Nanofluid in a Rotating System," Appl Nanosci, 5, 351360

http://dx.doi.org/10.1007/s13204-014-0324-3

Venkateswarlu, B., and Satya Narayana, P.V., 2015, "MHD ViscoElastic Fluid Flow over a Continuously Moving Vertical Surface with Chemical Reaction," Walailak J. sci. Eng., 12 (9), 775-783.

Wakif, A., Boulahia, Z., Amine, A., Animasaun, I.L., Afridi, M. I., Qasim, M., and Sehaqui, R., 2019, "Magneto-Convection of Alumina Water Nanofluid within thin Horizontal Layers using the Revised Generalized Buongiorno's Model," Frontiers In Heat And Mass Transfer, 12, 3, 1-15.

http://dx.doi.org/10.5098/Hmt.12.3.

Yongbin Zhang, 2017, "Influence of Pore Wall Surface Property on Flux of Cylindrical-Shaped Nanoporous Filtering Membrane," Frontiers in Heat and Mass Transfer, 9, 26, 1-6. http://dx.doi.org/10.5098/Hmt.9.26

Yashwant Singh, Rajesh Maithani, Sunil Kumar, and Ehsan Gholamalizadeh, Anil Kumar, 2018, "Development of New Correlations for Nusselt Number and Friction Factor of Tio2/Water Based Nanofluid Flow in V-Pattern Protrusion Ribbed Square Channel," Frontiers In Heat And Mass Transfer, 11, 33, 1-16. http://dx.doi.org/10.5098/Hmt.11.33. 